\title{
Drug Review on Echinocandins
}

\section{Sajith $\mathbf{M}^{*}$}

Department of Clinical Pharmacy, BharatiVidyapeeth Deemed University, India

*Corresponding author: Manjusha Sajith, Department of Clinical Pharmacy, Bharati

Vidyapeeth Deemed University, Poona College of Pharmacy, Pune, Maharashtra, India, Tel: +09730080959; E-mail: manjusaji1@yahoo.com

\section{Abstract}

Echinocandins are the newer addition to antifungal agents effective for Amphotericin B-resistant or fluconazole- and itraconazole-resistant Candida glabrata species. Echinocandins have fungicidal activity against multiple Candida species, including C. albicans, C. dubliniensis, C. glabrata, and C. krusei and fungistatic activity against Aspergillus species. These drugs inhibit the synthesis of the enzyme 1,3- $\beta$ glucan synthase which is necessary for the synthesis of an essential component of the cell wall of several fungi. Because of Echinocandins poor oral bioavailability, these drugs can only be administered intravenously. Echinocandins that currently are available include Caspofungin, Micafungin, and Anidulafungin. All three drugs are approved for the treatment of oesophageal candidiasis, candidaemia and other select forms of invasive candidiasis. Only micafungin is used to prevent Candida fungal infections in stem cell transplant patients, whereas caspofungin is approved for empirical therapy of febrile neutropenia. Caspofungin has a slightly higher potential for adverse effects/drug-drug interactions among these enchiniocandins and least observed for Anidulafungin. Due to the limited toxicity and a favorable drug-drug interactions profile make Echinocandins treatment as a viable alternative to conventional treatment.

Keywords: Echinocandin; Candida species candidiasis

\section{Introduction}

Despite recent advances in the antifungal armamentarium, candidemia and other forms of Invasive Candidiasis (IC) remain potentially fatal infections that result in significant morbidity, particularly in immune compromised and critically ill patients [1]. The spectrum of disease caused by the Candida ranges from non-lifethreatening muco-cutaneous infections to life-threatening invasive Candidiasis/Candidemia.Candidemia is the most common manifestations of invasive candidiasis. Candidaalbicans is one of the most common causes of candidemia, but in the recent years, there has been an increased isolation of non-albicans species of Candida. Most prominent have been Candidaglabrata and Candidaparapsilosis, followed by Candida tropicalis and Candida krusei. This is important because some Candida glabrata isolates and all $C$. kruseiisolates are resistant to fluconazole [2].

The most common antifungal agents used currently for the treatment of candidemia are fluconazole and the echinocandins. Formulations of amphotericin B are given less often due to the risk of toxicity [3]. As the incidence of 
fungal infections caused by fluconazole-resistant nonCandida-albicans species is increasing, echinocandins have become an important group in the treatment of these types of infections because of lack of cross-resistance to azoles [4]. Their limited toxicity and a favorable drug-drug interactions profile make them a viable alternative to conventional treatment.

Echinocandin antifungal was first discovered in the 1970s, and one of the first echinocandins of the pneumocandin type Echinocandin B, discovered in 1974 . Echinocandin B could not be used clinically due to risk of high degree of hemolysis [5]. A similar kind of antifungal activity was found in the semisynthetic pneumocandin analogs of echinocandins later on, but with low toxicity. The first approved of these newer echinocandins was caspofungin; later micafungin and anidulafungin were also approved.

Caspofungin has been approved by both the U.S Food and Drug Administration (FDA) and the European Union (EMEA) in 2001. Caspofungin is indicated in adults and pediatric patients (3 months and older) for empirical therapy, for presumed fungal infections in febrile neutropenic patients and in the treatment of some specific Candida infections such as intra-abdominal abscesses, peritonitis and pleural space infections, esophageal candidiasis and in the treatment of invasive aspergillosis in patients who are refractory to orintolerant of other therapies (e.g., amphotericin B, lipid formulations of amphotericin B, itraconazole) $[6,7]$.
Micafungin gained final approval from the U.S. FDA on March 16, 2005, and in the European Union on April 25, 2008. Micafungin is indicated for the treatment of candidemia, acute disseminated candidiasis, Candida peritonitis, abscesses and esophageal candidiasis. Since January 23, 2008, micafungin has been approved for the prophylaxisof Candida infections in patients undergoing hematopoietic stem cell transplantation [8].

Pfizer received approval for Anidulafungin by the FDA on February 21, 2006. It was previously known as LY303366. Preliminary evidence indicates it has a similar safety profile to caspofungin.Anidulafunginis was approved for candidemia and other forms of Candida infections (intra-abdominal abscess, and Candida peritonitis) and esophageal candidiasis $[8,9]$.

The echinocandins drugs are now preferred first-line therapy for patients with invasive candidiasis, and it has been reported that more than $60 \%$ of candidemia patients receive an echinocandin during therapy [10-12]. Given the clinical importance of echinocandins, this review focuses on mechanism, pharmacodynamics in vitro activity of different Echinocandins available in the market.

\section{Chemistry of Echinocandins}

Echinocandins are large lipopeptide molecules synthetically modified from the fermentations broths of various fungi. They are amphiphilic cyclic hexapeptides with N-linked acyl lipid side-chain and a molecular weight of about 1200 [10] (Table 1).

\begin{tabular}{|c|c|c|c|}
\hline $\begin{array}{c}\text { Molecular } \\
\text { formula }\end{array}$ & $\mathrm{C}_{52} \mathrm{H}_{88} \mathrm{~N}_{10} \mathrm{O}_{15} \cdot 2 \mathrm{C}_{2} \mathrm{H}_{4} \mathrm{O}_{2}$ & Micafungin & Anidulafungin \\
\hline Solubility & $\begin{array}{c}\mathrm{C}_{56} \mathrm{H}_{70} \mathrm{~N}_{9} \mathrm{NaO}_{23} \mathrm{~S} . \\
\text { freely soluble in water and methanol, and slightly } \\
\text { soluble in ethanol }\end{array}$ & freely soluble in water & $\mathrm{C}_{58} \mathrm{H}_{73} \mathrm{~N}_{7} \mathrm{O}_{17}$ \\
\hline $\begin{array}{c}\text { Chemical } \\
\text { structure }\end{array}$ & freely soluble in water \\
\hline
\end{tabular}

Table 1: Chemistry of echinocandin. 


\section{Pharmacology/Pharmacodynamics}

Echinocandins are noncompetitive inhibitors of 1,3- $\beta$-Dglucan synthase, an enzyme needed for the formation of $1,3-\beta$-D-glucan [13]. Glucan synthase is not found in mammalian cells, making it an ideal target for antifungal agents. Glucan is essential for fungal cell wall structure and growth, maintaining cell shape and rigidity, and resistance to osmotic pressure. Varying amounts of chitin, glucans, mannoproteins, and other cell wall constituents are present in different fungal species, making some species more susceptible to the echinocandins than others. 1,3- $\beta$ D-glucan is a major cell wall component of Candida and Aspergillus species, rendering them more vulnerable to agents found in this drug class.

\section{In vitro activity of Echinocandins}

Micafungin shows in vitro activity against Aspergillus species \& Candida species including Candida albicans, Glabrata, krusei, parapsilosis, and tropicalis while caspofungin exhibits in vitro activity against Aspergillus species including Aspergillus fumigatus, flavus, and terreus and Candida species including Candida albicans, Glabrata, guilliermondii, krusei, parapsilosis, and tropicalis. Anidulafungin exhibits in vitro activity against Candida species including Candida albicans, glabrata, parapsilosis, tropicalis, famata, rugosa, stellatoidea; Aspergillus species (A. fumigatus) and Other molds (Bipolaris spicifera, Exophiala jeanselme; Fonsecaea pedrosoi, Madurella spp., Penicillium marneffei, Phialophora verrucosa, Pseudallescheria boydii and Wangiella dermatitidis) [14].

At clinically relevant concentrations, Micafungin, caspofungin and anidulafungin are not active against Zygomycetes, Cryptococcus neoformans, Fusarium spp., or Trichosporon spp. It is important to note that the echinocandins are concentration-dependent agents, meaning that the rate and extent of antifungal activity are related to the concentration of the agent (i.e., increased concentration leads to increased kill). This characteristic is different from the azoles, which display time-dependent activity or increased antifungal activity with increased exposure to the drug [14].

\section{Dosage and Administration}

Anidulafungin and Micafungin are freely soluble in water. Caspofungin is freely soluble in water and methanol, and slightly soluble in ethanol. Because of their inconsistent oral absorption, echinocandins are available only for intravenous use.

The dosage of Caspofungin acetate for candidemia and other candida infections, invasive aspergillosis, and febrile neutropenia is a single 70-mg i.v. loading dose administered on day 1 , followed by $50 \mathrm{mg}$ daily thereafter. For esophageal candidiasis, the dosage of caspofungin acetate is $50 \mathrm{mg}$ daily. A loading dose has not been studied for this indication [8]. Recommended dosing of caspofungin in Pediatric Patients [3 months to 17 years of age] for all indications, is a single $70 \mathrm{mg} / \mathrm{m}^{2}$ loading dose should be administered on Day 1, followed by $50 \mathrm{mg} / \mathrm{m}^{2}$ once daily thereafter. Regardless of the patient's calculated dose, the maximum loading dose and the daily maintenance dose should not exceed $70 \mathrm{mg}$, Dosing in pediatric patients should be based on the patient's body surface area (BSA) [7].

The dosage of micafungin sodium for the prophylaxis of candida infections is $50 \mathrm{mg}$ i.v. daily. Treatment of esophageal candidiasis requires a dosage of $150 \mathrm{mg}$ i.v. daily. A micafungin sodium dosage of $100 \mathrm{mg}$ i.v. daily was used in a large trial of candidemia treatment and demonstrated no difference in overall treatment success between micafungin sodium $100 \mathrm{mg}$ i.v. daily and liposomal amphotericin B $3 \mathrm{mg} / \mathrm{kg}$ daily. Of note, $85 \%$ of steady-state concentration is achieved after three daily doses; therefore, no loading dose is required for micafungin.

The recommended dose of Anidulafungin for Candidemia and Other Candida Infections (IntraAbdominal Abscess, And Peritonitis) is a single $200 \mathrm{mg}$ loading dose on Day 1, followed by $100 \mathrm{mg}$ daily dose thereafter. Duration of treatment should be based on the patient's clinical response. In general, antifungal therapy should continue for at least 14 days after the last positive culture.

The recommended dose of Anidulafungin for Esophageal Candidiasis is a single $100 \mathrm{mg}$ loading dose on Day 1 , followed by $50 \mathrm{mg}$ daily dose thereafter. Patients should be treated for a minimum of 14 days and for at least 7 days following resolution of symptoms. Duration of treatment should be based on the patient's clinical response. Because of the risk of relapse of esophageal candidiasis in patients with HIV infections, suppressive antifungal therapy may be considered after a course of treatment (Table 2). 


\begin{tabular}{|c|c|c|}
\hline Echinocandins & Special population & Dose considerations \\
\hline \multirow{6}{*}{ Caspofungin } & $\begin{array}{l}\text { Patients with renal } \\
\text { insufficiency }\end{array}$ & No dosage adjustment is required \\
\hline & Hepatic insufficiency & $\begin{array}{l}\text { AUC of Caspofungin is significantly increased in patients with hepatic insufficiency } \\
\text { and hence, it is suggested that dose of Caspofungin be decreased from } 50 \mathrm{mg} \text { to } \\
35 \mathrm{mg} \text { daily in patients with moderate hepatic insufficiency }\end{array}$ \\
\hline & Paediatrics & $\begin{array}{l}\text { Weight-based dosing in children resulted in lower plasma concentrations as } \\
\text { compared to adults whereas dosing based on body surface area }(\mathrm{mg} / \mathrm{m} 2 / \text { day) } \\
\text { tesulted in steady plasma state concentration same as adults receiving } 50 \mathrm{mg} \text { dose }\end{array}$ \\
\hline & Nursing mothers & $\begin{array}{l}\text { Caspofungin was found in the milk of lactating drug treated rats and hence, should } \\
\text { be exercised with caution when echinocandins are administered to a nursing } \\
\text { woman }\end{array}$ \\
\hline & Pregnancy & $\begin{array}{c}\text { Categorized as Pregnancy Category C and should be used only if the potential } \\
\text { benefit justifies the risk to the fetus }\end{array}$ \\
\hline & Geriatric use & No dosage adjustments are required \\
\hline \multirow{5}{*}{ Micafungin } & $\begin{array}{l}\text { Patients with renal } \\
\text { insufficiency }\end{array}$ & No dosage adjustments is required \\
\hline & Hepatic insufficiency & $\begin{array}{l}\text { In patients receiving micafungin, dosage adjustments are not recommended for } \\
\text { patients with moderate hepatic dysfunction. }\end{array}$ \\
\hline & Paediatrics & $\begin{array}{l}\text { According to dose-escalation study in paediatric patients, increase in the } \\
\text { clearance of micafungin was noted in patients } 2-8 \text { years of age. Hence, } \\
\text { ecommended that a dosage of } 1.5 \text { times that of the adult dosage be utilized in this } \\
\text { population }\end{array}$ \\
\hline & Nursing mothers & $\begin{array}{l}\text { Micafungin was found in the milk of lactating drug treated rats and hence, should } \\
\text { be exercised with caution when echinocandins are administered to a nursing } \\
\text { woman }\end{array}$ \\
\hline & Pregnancy & $\begin{array}{c}\text { Categorized as Pregnancy Category C and should be used only if the potential } \\
\text { benefit justifies the risk to the fetus }\end{array}$ \\
\hline \multirow{6}{*}{ Anidulafungin } & $\begin{array}{l}\text { Patients with renal } \\
\text { insufficiency }\end{array}$ & No dosage adjustment is required \\
\hline & Hepatic insufficiency & $\begin{array}{c}\text { Dosage adjustments are not suggested for patients with mild, moderate, or severe } \\
\text { hepatic dysfunction who are receiving anidulafungin }\end{array}$ \\
\hline & Paediatrics & $\begin{array}{l}\text { Concentrations and exposures following administration of maintenance doses of } \\
0.75 \mathrm{mg} / \mathrm{kg} / \text { day and } 1.5 \mathrm{mg} / \mathrm{kg} / \text { day were similar to those observed in adults } \\
\text { following maintenance doses of } 50 \mathrm{mg} / \text { day and } 100 \mathrm{mg} / \text { day, respectively. }\end{array}$ \\
\hline & Nursing mothers & $\begin{array}{l}\text { Anidulafungin was found in the milk of lactating drug treated rats and hence, } \\
\text { should be exercised with caution when echinocandins are administered to a } \\
\text { nursing woman }\end{array}$ \\
\hline & Pregnancy & $\begin{array}{c}\text { Categorized as Pregnancy Category } \mathrm{C} \text { and should be used only if the potential } \\
\text { benefit justifies the risk to the fetus }\end{array}$ \\
\hline & Geriatric use & Range of clearance is similar in elderly and nonelderly subjects. \\
\hline
\end{tabular}

Table 2: Dose consideration of echinocandins in special populations [7-9].

\section{Safety and Efficacy}

In general, all the three echinocandins are welltolerated. While there appear to be a few differences between these agents, caspofungin has been on the market for much longer than both micafungin and anidulafungin.
Caspofungin and Micafungin are considered to be safe in pediatric patients [15-18]. The safety and effectiveness of anidulafungin in pediatric patients has not been yet established [9]. Echinocandins are contraindicated in patients with known hypersensitivity to the agents or any of its components. They have an approving safety profile 
compared to other antifungals. Infusion related reactions may occur after use of all three echinocandins $(<5 \%)$, but the drug is not necessary to be withdrawn as they respond well to antihistamines [19]. Also, thrombophlebitis may occur $(<3 \%$; primarily seen in HIV infected patients with peripheral lines). Caspofungin has a somewhat shown a higher frequency of liver-related laboratory abnormalities (1-15\%) when compared to the other two drugs. Nausea, vomiting, diarrhea and other mild gastrointestinal symptoms are possible. As micafungin lacks antagonism, it makes it preferable to combine it with other antifungals. Micafungin is well tolerated and also there is no associated dose or duration related toxicities. Hyperbilirubinemia (3.3\%), nausea (2.4\%), diarrhea (2.1\%), leukopenia, and eosinophilia have been reported; patients receiving micafungin have also reported local phlebitis and thrombophlebitis at the injection site. Also, the drug has no significant effect on renal function. From the overall reported adverse event rate of $46 \%$, only $5 \%$ were directly associated with Anidulafungin. The most common adverse events included hypotension (13\%), vomiting (13\%), constipation (11\%), nausea (11\%) and pyrexia (11\%), but none are dose dependent [20-22] (Table 3).

\begin{tabular}{|c|c|c|}
\hline Echinocandins & Drugs & Effect \\
\hline \multirow{4}{*}{ Caspofungin } & Cyclosporine & $\begin{array}{l}\text { Transient increases in liver enzymes ALT and AST when these drugs were co- } \\
\text { administered. Monitor patients liver enzymes during concomitant therapy. }\end{array}$ \\
\hline & Tacrolimus & $\begin{array}{c}\text { For patients receiving these drugs standard monitoring of tacrolimus trough } \\
\text { whole blood concentrations and appropriate tacrolimus dosage adjustments } \\
\text { are recommended. }\end{array}$ \\
\hline & Ciclosporin & $\begin{array}{c}\text { resulting in raised caspofungin plasma concentrations (35\% increase in area } \\
\text { under the curve) but no change in amount of ciclosporin in whole blood. The } \\
\text { mechanism of this interaction is unclear. }\end{array}$ \\
\hline & Enzyme inducers & $\begin{array}{l}\text { When caspofungin is given with the enzyme-inducing drugs rifampin, } \\
\text { efavirenz, nevirapine, phenytoin, dexamethasone, or carbamazepine, the } \\
\text { daily dose of caspofungin should be increased to } 70 \text { mg since these agents } \\
\text { may cause a clinically meaningful reduction in caspofungin levels. }\end{array}$ \\
\hline \multirow{3}{*}{ Micafungin } & Nifedipine & $\begin{array}{l}\text { Nifedipine AUC and Cmax were increased by } 18 \% \text { and } 42 \% \text {, respectively } \\
\text {.Patients receiving Nifedipine in combination with Micafungin should be } \\
\text { monitored for Nifedipine toxicity and Nifedipine dosage should be reduced if } \\
\text { necessary. }\end{array}$ \\
\hline & $\begin{array}{l}\text { Mycophenolate Mofetil, } \\
\text { Cyclosporine, Tacrolimus, } \\
\text { Prednisolone, and } \\
\text { fluconazole }\end{array}$ & $\begin{array}{l}\text { There was no effect of a single dose or multiple doses of Micafungin on } \\
\text { mycophenolate mofetil, cyclosporine, tacrolimus, prednisolone, and } \\
\text { fluconazole pharmacokinetics. }\end{array}$ \\
\hline & Sirolimus & $\begin{array}{c}\text { Increases the AUC of sirolimus by } 21 \% \text { with no effect on Cmax in the } \\
\text { presence of steady-state. Patients receiving sirolimus in combination with } \\
\text { Micafungin should be monitored for sirolimus toxicity and sirolimus dosage } \\
\text { should be reduced if necessary. }\end{array}$ \\
\hline Anidulafungin & cyclosporin & $\begin{array}{l}\text { Cyclosporin also increases the AUC of anidulafung (22\%). No dosage } \\
\text { adjustment of either drug is warranted when co-administered. }\end{array}$ \\
\hline
\end{tabular}

Table 3: Reported Drug interactions of Echinocandins [23-28]. 


\section{Conclusion}

The echinocandins are superior antifungals due to their novel mechanism of action, lower incidence of serious adverse effects, and low potential for drug-drug interactions. Being antifungal class, they demonstrate potent activity against Candida species and are also the treatment choices for infections due to these organisms. Echinocandins have revealed their potent activity against infections like invasive candidiasis, esophageal candidiasis and candidemia. In addition, Micafungin and Caspofungin are remarkably similar. They have similar microbial spectrum of activity with only minor changes in pharmacokinetics, pharmacodynamics, adverse effects and drug interactions. Echinocandins can also serve as a choice of treatment when other antifungals prove to be resistant in the infections. Convenient dosing, an excellent safety profile, and remarkably few drug interactions make echinocandins a welcome addition to the expanding antifungal armamentarium.

As a class, the echinocandins possess many pharmacokinetic similarities, including low oral bioavailability, high protein binding, and relatively low CSF and urine concentrations of parent drug. Echinocandins are poorly absorbed when administered orally. On intravenous administration, they will reach most tissues and organs with concentrations sufficient to treat the localized and systemic fungal infections. Anidulafungin, caspofungin, and micafungin differ most importantly by the manner they are eliminated from the human body. Elimination of anidulafungin occurs slowly by chemical degradation throughout the body whereas micafungin is primarily eliminated in the liver by hydrolysis, a process seldom involved in drug interactions. Caspofungin is eliminated partially through chemical degradation and partially through the liver by hydrolysis. Very little of these drugs is eliminated by the kidneys.

\section{References}

1. Neoh CF, Liew D, Slavin M, Marriott D, Chen SC, et al. (2011) Cost-effectiveness analysis of anidulafungin versus fluconazole for the treatment of invasive candidiasis. J Antimicrob Chemother 66(8): 19061915.

2. Carol A Kauffman, Kieren A Marr, Anna R Thorner (2018) Treatment of candidemia and invasive candidiasis in adults.

3. Gafter-Gvili A, Vidal L, Goldberg E, Leibovici L, Paul M (2008) Treatment of invasive candidal infections: systematic review and meta-analysis. Mayo Clin Proc 83(9): 1011-1021.

4. Ostrosky-Zeichner L, Pappas PG (2006) Invasive candidiasis in the intensive care unit. Crit Care Med 34(3): 857-863.

5. Nyfeler R, Keller SW (1974) Metabolites of microorganisms, 143: echinocandin B, a novel polypeptide-antibiotic from Aspergillus nidulans var echinulatus-isolation and structural components. Helv Chim Acta 57: 2459-2477.

6. Stone EA, Fung HB, Kirschenbaum HL, Horatio B Fung (2002) Caspofungin: an echinocandin antifungal agent. Clin Ther 24(3): 351-377.

7. (2005) Caspofungin package insert, Cancidas (caspofungin acetate) For Injection, Whitehouse Station, NJ 08889, USA: Merck \& Co.

8. US Food and Drug Administration Center for Drug Evaluation and Research. A catalog of FDA approved drug productions.

9. (2006) Eraxis [package insert], Eraxis (anidulafungin) For Injection. New York, NY: Pfizer.

10. Pappas PG, Kauffman CA, Andes D, Benjamin DK Jr, Calandra TF, et al. (2009) Clinical practice guidelines for the management of candidiasis: 2009 update by the Infectious Diseases Society of America. Clin Infect Dis. 48(5): 503-535.

11. Cleveland AA, Farley MM, Harrison LH, Stein B, Hollick $R$, et al. (2012) Changes in incidence and antifungal drug resistance in candidemia: results from population-based laboratory surveillance in Atlanta and Baltimore, 2008-2011. Clin Infect Dis 55(10): 1352-1361.

12. Perlin DS (2015) Mechanisms of echinocandin antifungal drug resistance. Ann N Y Acad Sci. 1354(1): $1-11$.

13. Boucher HW, Groll AH, Chiou CC, Walsh TJ (2004) Newer systemic antifungal agents: pharmacokinetics, safety and efficacy. Drugs 64(18): 1997-2020.

14. Gil-Alonso S, Jauregizar N, Cantón E, Eraso E, Quindós $G$ (2015) Comparison of the in vitro activity of echinocandins against Candida albicans, Candida dubliniensis, and Candida africana by time-kill curves. Diagn Microbiol Infect Dis 82(1): 57-61. 
15. Odio CM, Araya R, Pinto LE, Castro CE, Vasquez S, et al. (2004) Caspofungin therapy of neonates with invasive candidiasis. Pediatr Infect Dis J 23(12): 1093-1097.

16. van Burik JA, Ratanatharathorn V, Stepan DE, Miller CB, Lipton JH, et al. (2004) Micafungin versus fluconazole for prophylaxis against invasive fungal infections during neutropenia in patients undergoing hematopoietic stem cell transplantation. Clin Infect Dis 39(10): 1407-1416.

17. Groll AH, Stergiopoulou T, Roilides E, Walsh TJ (2005) Micafungin: pharmacology, experimental therapeutics and clinical applications. Expert Opin Investig Drugs 14(4): 489-509.

18. Walsh TJ, Adamson PC, Seibel NL, Flynn PM, Neely MN, et al. (2005) Pharmacokinetics, safety, and tolerability of caspofungin in children and adolescents. Antimicrob Agents Chemother 49(11): 4536-4545.

19. Vazquez JA (2005) Anidulafungin: a new echinocandin with a novel profile. Clin Ther 27(6): 657-673.

20. (2001) Cancidas, caspofungin [package insert]. Whitehouse Station, NJ, USA: Merck \& Co.

21. (2007) Astellas Pharma US, Inc. Mycamine [package insert], Mycamine (micafungin sodium) For Injection, Deerfield, IL: Astellas Pharma US.

22. David W Dening (2002) Echinocandin: a new class of antigungal. Journal of Antimicrobial Chemotherapy 49(6): 889-891.
23. Perea S, Gonzalez G, Fothergill AW, Kirkpatrick WR, Rinaldi MG, et al. (2002) In vitro interaction of caspofungin acetate with voriconazole against clinical isolates of Aspergillus spp. Antimicrob Agents Chemother 46(9): 3039-3041.

24. Sable Ca, Nguyen BY, Chodakewitz JA, DiNubile MJ (2002) safety and tolerability of caspofungin acetate in the treatment of fungal infections. Transpl Infect dis 4(1): 25-30.

25. Manavathu EK, Krishnan S, Cutright JL, Chandrasekar PH (2000) A comparative study of the in vitro susceptibility of Aspergillusfumigatustoantifungal agents individually and in combination by the fractionalinhibitory concentration index, tetrazolium reduction and radiometric assays.

26. Chen YL, Lehman VN, Averette AF, Perfect JR, Heitman J (2013) Posaconazole Exhibits In Vitro and In Vivo SynergisticAntifungal Activity with Caspofungin or FK506 againstCandidaalbicans. PLoS One 8(3): e57672.

27. Townsend, Robert \& Hebert, Mary \& Wisemandle, W \& Bekersky, I (2002) Concomitant pharmacokinetics (PK) of micafungin, an echinocandin antifungal, and cyclosporine in healthy volunteers. The Journal of Clinical Pharmacology 42: 1054.

28. Hebert MF, Blough DK, Townsend RW, Allison M, Buell $\mathrm{D}$, et al. (2005) Concomitant tacrolimus and micafungin pharmacokinetics in healthy volunteers. J Clin Pharmacol 45(9): 1018-1024. 